Meta

Journal des traducteurs

Translators' Journal

\title{
How Do Language Professionals Organize Themselves? An Overview of Translation Networks
}

\section{Julie McDonough}

Volume 52, numéro 4, décembre 2007

La traduction et les études de réseaux

Translation and Network Studies

URI : https://id.erudit.org/iderudit/017697ar

DOI : https://doi.org/10.7202/017697ar

Aller au sommaire du numéro

Éditeur(s)

Les Presses de l'Université de Montréal

ISSN

0026-0452 (imprimé)

1492-1421 (numérique)

Découvrir la revue

Citer cet article

McDonough, J. (2007). How Do Language Professionals Organize Themselves? An Overview of Translation Networks. Meta, 52(4), 793-815.

https://doi.org/10.7202/017697ar
Résumé de l'article

Cet article propose un cadre visant à classer et à décrire les réseaux de traduction. Sont définies quatre catégories de réseaux en fonction de l'aspect de la traduction sur lequel les acteurs mettent l'accent : la profession, la pratique, l'enseignement ou la recherche. On porte également un regard sur diverses variables qui touchent la structure et la composition des réseaux de traduction afin de mieux préciser les caractéristiques de chaque catégorie. Enfin, on analyse le réseau TranslatorsCafé afin de proposer des pistes de recherche pour des études ultérieures. 


\title{
How Do Language Professionals Organize Themselves? An Overview of Translation Networks
}

\author{
JULIE MCDONOUGH \\ University of Ottawa, Ottawa, Canada \\ julielaura.mcdonough@uottawa.ca
}

\begin{abstract}
RÉSUMÉ
Cet article propose un cadre visant à classer et à décrire les réseaux de traduction. Sont définies quatre catégories de réseaux en fonction de l'aspect de la traduction sur lequel les acteurs mettent l'accent: la profession, la pratique, l'enseignement ou la recherche. On porte également un regard sur diverses variables qui touchent la structure et la composition des réseaux de traduction afin de mieux préciser les caractéristiques de chaque catégorie. Enfin, on analyse le réseau TranslatorsCafé afin de proposer des pistes de recherche pour des études ultérieures.
\end{abstract}

\section{ABSTRACT}

This paper provides a framework for categorizing and describing translation networks. It defines and outlines four main categories of translation networks: profession-oriented, practice-oriented, education-oriented and research-oriented. To better describe these networks, variables affecting their structure and composition are also explored. Finally, the TranslatorsCafé network is analyzed to demonstrate how this framework could be applied to future studies.

\section{MOTS-CLÉS/KEYWORDS}

translation networks, online communities, weak ties, strong ties, professional associations

\section{Introduction $^{1}$}

Networking is an important aspect of the translation profession. Through translation networks, translators, interpreters, terminologists, localizers, researchers and other language professionals are able to collaborate, exchange services and learn about new trends or innovations in the field. For many freelancers, large international online networks are a way to interact with other translators and secure new contracts. Inhouse translators are linked with other colleagues working at the company and may also be part of larger networks of professionals, such as a professional order or an online discussion group. Students and newcomers to the field often join translation networks to learn from more experienced professionals. Researchers may collaborate with other colleagues to generate and disseminate knowledge. Determining the characteristics of translation networks is essential to understanding how translators and other language professionals organize themselves. Categorizing these networks will also provide a foundation for further study of the role networks play in translation practices. 


\section{Categorizing translation networks}

\subsection{Defining translation networks}

A network can be conceived of as a spatially diffuse structure with undefined boundaries (Gross Stein and Stren 2001: 5). This means networks are flexible, adapt to changing environments, and expand and contract over time. These spatially diffuse structures are made up of nodes (or actors) sharing common interests or values and linked together through interdependent relationships of exchange (c.f. Gross Stein and Stren 2001: 5; Wasserman and Faust 1994: 17). ${ }^{2}$ Nodes do not have to be individuals; they can also be groups, departments, corporations, networks, countries, etc. (Wellman and Berkowitz 1988: 4; Wasserman and Faust 1994: 17).

A translation network, then, is one in which the actors share a common interest in translation or a translation-related profession (e.g. interpreting or terminology). ${ }^{3}$ In the translation networks studied here, the interdependent relationships linking actors usually involved exchanges of material resources, such as translation for payment, or non-material resources such as questions, answers, advice and announcements related to translation, such as terminology, research and job opportunities. Other terms, including organization, order, association and federation, are often used to describe or identify translation networks. The above definition is also broad enough to include (multi-)national translation agencies, which are comprised of translators and project managers linked through an exchange of translation services for payment.

Throughout this paper, the term translation network is used to refer to a network composed of actors with a shared interest in translation and/or related activities, including interpretation, terminology, bilingual revision and globalization, internationalization, localization, translation (GILT). Networks with a focus on technical, scientific or other writing have been considered translation networks only when they focus on writing and a translation-related activity.

The term language professional will be used to refer to anyone working in a translation-related field such as translation, interpretation, terminology, and localization. In all cases, a field has been deemed to be translation-related when it involves more than one language. Thus, bilingual revision would be considered a translationrelated profession, while monolingual revision would not. While defining the term professional is problematic, ${ }^{4}$ the term has been chosen to refer to anyone who practices a translation-related profession, whether on a full- or part-time basis, and earns an income from this work. It thus includes professors and researchers in the field, as well as independent and in-house translators, interpreters, terminologists, subtitlers, localizers, etc. The key distinction in this paper between a professional and a nonprofessional is made on the basis of income. Someone who has never exchanged a language-related service for a fee but who has an interest in the field is referred to as either a non-professional or a student, depending on whether he or she is currently enrolled in a language-related program. In section 1.3, the notion of professional is explored in slightly more depth when the variables affecting the attributes of actors in a translation network are compared. 


\subsection{Methodology}

For this typology of translation networks, the websites of more than forty networks were studied in detail and the mandates, structures and membership requirements of the networks compared. This comparison brought to light four general interests that seemed to link actors in most of the forty networks. Four categories were therefore drawn up to reflect these interests and several dozen additional networks were then briefly examined to determine whether they fell into the tentative categories.

The initial translation networks were found online through search engine queries for translation network, association, organization and group. Effort was made to search for networks in as many countries as possible to ensure that the categories did not apply only to translation networks composed primarily of actors from Canada. As with all research, however, this effort was subject to certain limitations: networks that did not have a web presence and offer information in English, French or Spanish were not analyzed.

Because a number of translation networks are composed of actors who interact primarily through online services such as msn Groups, Yahoo! Groups and Google Groups, searches were also conducted in all three of these services to determine how many translation networks existed and what interests linked the actors. Because msn, Yahoo! and Google host a considerable number of translation-related groups - more than 800 groups focusing on various practical or professional aspects of translation, including terminology, jobs and industry news, are listed under Translation and Interpretation by Yahoo! Groups alone - a large number of networks could be consulted relatively easily.

Although the above methodology would seem to exclude networks whose members do not rely on computer-mediated communication to interact, other networks have also been considered and seem, for the most part, to fall into one of the four broad categories described in section 1.2.

This method of categorization is certainly not the only means of organizing translation networks. However, it was chosen because it seemed the best way to reflect the unique characteristics of translation networks, rather than networks in general. Adopting one of the categorization methods typically found in the social sciences did not seem to offer a perspective specific to translation. Categorizing translation networks into one- or two-mode networks, for instance (c.f. Wasserman and Faust 1994: 35-43), would not have shed light on what makes networks of language professionals different from networks of other professionals.

One advantage to the framework proposed below, however, is that it does not prevent researchers from adopting it for a study that also uses another method of categorization. One could, for instance, study how affiliation networks differ among the four categories of translation networks. Affiliation networks are those in which actors are linked to one another by their joint participation in social events (c.f. Wasserman and Faust 1994: 291-293). Using the categories proposed in section 1.2, one could begin with a single actor - for example, a freelance Portuguese-French translator - and then determine which translation-related social events the actor attends. One could also study how often a group of actors in a research-oriented network, for instance, attends social events related to translation, though not necessarily related only to research aspects of translation. Such studies would shed light 
on how many types of networks a single actor belongs to. In the case of the Portuguese-French freelancer, this study would allow the researcher to draw conclusions about the types of networks the freelancer belongs to and how membership in multiple types of networks might affect the work the translator produces (c.f. Wasserman and Faust 1994: 53). The categories are therefore flexible enough for a variety of studies, but specific enough to show how translators and other language professionals have organized themselves and what interests link them together.

\subsection{Translation network categories}

Actors in translation networks seem to be linked by a shared interest in a few broad aspects of translation. Thus, most translation networks fall into one of four main categories. In this section, these four categories are proposed and outlined. They are based on the translation-related interests or values shared by the actors in a network. While actors could be linked together by a wide variety of translation interests and values, most, if not all, translation networks can be described as profession-oriented, practice-oriented, education-oriented, research-oriented or some combination of the four. Although the networks in each category share many similar characteristics, they also differ in a number of ways. Therefore, variables affecting the structure and composition of translation networks are explored in section 1.3.

\subsubsection{Profession-oriented networks}

In profession-oriented networks, actors are linked by a common interest in promoting translation as a professional activity. The focus of the network is not the actual act of translation itself but, rather, activities, events, problems and issues related to language-related professions, including defending the rights of language professionals, promoting professionalism, enhancing the status of language professionals and improving working conditions. Some of these networks, such as the International Federation of Translators, the Literary Translators' Association of Canada (LTAC), the Organización Mexicana de Traductores and the South African Translators' Institute, exist to advance recognition of the profession and enhance the status of translators in society. Many services related to the profession are available to members of these networks: some networks provide accreditation, allowing members to recognize the skill of their peers, some offer scholarships, prizes and awards to recognize excellence in the profession, while others offer professional development workshops or conferences so that members can make contacts and discuss issues related to the profession.

Profession-oriented networks composed of individual language professionals include the Sección Autónoma de Traductores de Libros de la Asociación Colegial de Escritores de España (ACEtt), the Ordre des traducteurs, terminologues et interprètes agréés du Québec (OTTIAQ), the American Translators Association (ATA), the Union Nationale des Experts Traducteurs-Interprètes près des Cours d'Appel (UNETICA) and the Asociación Argentina de Traductores e Intérpretes (AATI). In other profession-oriented networks, such as the Belgian Quality Translation Association (BQTA) and the Association of Translation Companies (ATC), the actors are not individuals, but, rather, translation companies. The BQTA is composed of translation companies in Belgium whose aims include "promot[ing] and maintain[ing] 
contact between translation companies in accordance with a strict professional code of ethics" and "contribut[ing] towards enhancing the image and the quality of the language services sector" (http://www.bqta.be/who\%20we\%20are.html), while the ATC consists of translation companies from around the world that agree to adhere to "a strict code of professional conduct," to be "subject to the rulings of a professional ethics committee" and to "carry full professional indemnity insurance" (http://www. atc.org.uk/index.html).

\subsubsection{Practice-oriented networks}

In practice-oriented networks, the common interest linking members is the actual performance or process of translation-related activities. Actors may also be linked by a relationship of business transactions or by exchanges of non-material resources, such as discussions about marketing strategies and terminological and technical problems encountered during the translation or interpretation process

Many practice-oriented networks can be found on the Internet. With more than 170,000 members (Kidd 2007), ProZ.com is the largest of these. It allows actors in the network to "outsource and accept translation and interpretation assignments, collaborate on terms with propriety $\mathrm{KudoZ}^{\mathrm{mu}}$ software, evaluate clients with the memberbuilt Blue Board ${ }^{\mathrm{Tn}}$, [and] meet face-to-face at local conferences and Powwows ${ }^{\mathrm{Tm}}$ " (http://www.proz.com/?sp=info/index\&ssp=intro). Focus here is obviously placed on activities directly related to the translation process, rather than on promoting professionalism or industry standards. While a glance at recent forum postings shows that many actors in the ProZ network do discuss these latter issues, the emphasis on terminology exchange, obtaining contracts and evaluating outsourcers makes ProZ a mainly practice-oriented network.

Other online practice-oriented networks operate primarily through services such as Yahoo!, Google, and msn Groups or chat services such as IRC (e.g. \#translators). These groups range in size from a few thousand members (e.g. Yahoo! Groups tr_jobs, which has 4866 members, and wordfast, which has 4691) to small networks with a few hundred or a few dozen members (e.g. Google Group Translation Jobs, which has 388 members, msn Group Thai Translators and Interpreters, which has 67 members and Google Group Greek Translation, which has only 8).

Still other practice-oriented networks include organizations of professional translators providing translating services, such as translation agencies or companies. The Russian Interpreters Network, for instance, is a network "wholly owned by members who are full-time professional Russian interpreters" (http://www.russianinterpreter.org/html/about_rin.html). Here, the actors in the network are linked together by the practice of translation and for the purpose of obtaining employment. Though a secondary focus of this network might be to recognize that members of this network are professionals or to promote professionalism among members, the primary mandate is to provide translation services to clients, and hence focus is placed on the act of translating.

\subsubsection{Education-oriented networks}

Education-oriented networks focus on the issues related to the teaching of translation. Interests linking actors include translator/interpreter training and curriculum development for translation and interpretation programs. A network such as the Canadian 
Association of Schools of Translation (CAST) "groups together universities offering translation programs and serves as a forum for them to ensure that their translators, terminologists, and interpreters receive the best possible training," according to the CAST homepage. Actors in education-oriented networks may be individuals, such as university and college professors, or organizations, such as academic institutions, departments and associations.

\subsubsection{Research-oriented networks}

Research-oriented networks focus on translation as a field of study and thus on translation studies, intercultural studies, translation technologies, comparative literature or a related field. This does not mean, however, that all research-oriented networks are actively engaged in conducting a particular research project or series of projects. Some research-oriented networks, such as the Centre for Translation and Textual Studies (CTTS) or the Intercultural Studies Group, are indeed researchdriven knowledge networks, but others, including the Canadian Association for Translation Studies (CATS), the American Translation and Interpreting Studies Association (ATISA), and the European Society for Translation Studies (EST) are not. The main interest linking members of these latter networks is to "bring together researchers, teachers and practitioners interested in the study or teaching of translation and related disciplines" (CATS), "encourage, support, and further the study of translation studies" (ATISA), or "promote research in the field of translation and interpretation" (EST). The focus of such networks is therefore on translation research in general or on bringing together researchers to further the study of translation.

Gross Stein and Stren (2001) use the term knowledge networks to refer to networks with a mandate to produce and disseminate knowledge (2001: 3-4). Such networks have no rigid boundaries, and knowledge is shared across political and social boundaries (2001: 7-8). Because research-oriented translation networks focus on producing and distributing research in the field of translation studies - by bringing together researchers so that they can exchange ideas and knowledge about the field, and/or by providing a means for researchers to collaborate on a project - they can be considered knowledge networks.

\subsection{Variables operating on translation networks}

Each category listed in section 1.2 shares a defining characteristic. Actors are linked by a shared interest in the profession, practice, teaching or study of translation. As with any attempt at categorization, however, the line between the categories is sometimes difficult to draw. Many profession-oriented networks, such as OTTIAQ or the ATA, offer practical seminars and training workshops, and some (e.g. ATA) host conferences where both academics and non-academics present papers. Still, the primary purpose of the conferences and workshops is professional development, in line with the network's focus on professionalism, which makes the general "professionoriented" label appropriate. ${ }^{5}$

Nonetheless, some networks might be better classified as a combination of two or more categories. Consider the Yahoo! group Russian Language Translators (ruslantra), a network of translators and interpreters who "discuss all aspects of translation and interpretation, including 1) theory and practice of scientific, technical and 
literary translation, 2) localization, 3) terminology, 4) extralinguistic issues, 5) rates and payment, and 6) culture" (http://tech.groups.yahoo.com/group/ruslantra/). This network might be best described as both practice- and research-oriented. So, when particular emphasis is placed on one aspect of translation, a network is best described as a single category, whereas networks where equal emphasis is placed on several aspects are best described as a combination of two or more categories.

Whether they fall easily into a single category or belong to several, all translation networks are still affected by a number of variables. Even networks within the same category will differ greatly in structure and composition. That is, the ties and types of exchanges among actors will differ from one translation network to another, as will the attributes of the actors (c.f. Wasserman and Faust 1994: 29). For instance, actors in one practice-oriented network may be linked through a relationship of business transactions. In another practice-oriented network, actors may be linked primarily through exchanges of terminology questions and answers. And while one scholarly network may be composed of only tenured university professors, another might include students, professors, independent researchers and other individuals interested in translation studies. Finally, the way in which the exchanges are mediated will also vary from one network to another: actors in some networks rely heavily on computer-mediated communication to interact, while those in other networks do not. Such variables, outlined below, need to be considered when analyzing translation networks.

\subsubsection{Sub-focus}

The term focus has thus far been used to refer to the general interests linking the actors in a translation network: the profession, practice, teaching or study of translation. However, within each category are networks of actors linked by a shared interest in specific or general sub-foci. Actors may be connected by many translation-related interests or only a few. Thus, a profession-oriented network like the ALTA, which, according to the association's homepage, "was founded in 1978 to provide essential services to literary translators from all languages and create a professional forum for the exchange of ideas on the art and craft of literary translation" (emphasis added), has a more specific sub-focus than the Localization World Network (LWN), which is a "networking environment, where individual people find others who share their interests" in one or more areas within a taxonomy that includes standards, translation management, automation, localization, content engineering, and training (Localization World Network n.d.: 2-3). In turn, the practice-oriented Network of Translators in Education (NTE), whose members are linked by a shared interest in harmonizing French and English terminology usage in education in Canada, has a very specific sub-focus in comparison with the practice-oriented network French_translation, which operates via Yahoo! Groups and is composed of members with an interest in translation to and from French, regardless of the subject field.

Thus, sub-foci of translation networks may be language pair(s) (e.g. The Spanish Network of the Institute of Translation and Interpreting), text type(s) (e.g. the LTAC, the Institute of Scientific and Technical Communicators (ISTC), or the Yahoo! Group Manga_Translations), one or more translation-related professions (e.g. ATIO, the Association of Translators and Interpreters of Ontario (ATIO) or avtranslators.org, a network of subtitlers, dubbers and adapters), subject field(s) (e.g. the Law, Insurance 
and Financial Translation Network of the Institute of Translation and Interpreting), etc. And of course, any network may be composed of actors with an interest in multiple sub-foci. For instance, the Network of Translators in Education has four subfoci: terminology (translation profession) in French and English (language pair) in Canada (geographic location) with respect to education (subject field).

\subsubsection{Values}

As discussed in section 1.0, networks are comprised of actors with common interests or values. Thus far, the focus of this paper has been on actors with an interest in translation, and the values part of the definition has been neglected. It is important to note, however, that actors may also be linked by both an interest in a translationrelated field and a shared set of values (beliefs or principles) related to this interest. Translators for Peace, for instance, is a practice-oriented network of translators with a mandate to "publish, as far as possible in every language and by whatever channel, every message against: war in general; and in particular, against the use of war as a means of resolving international disputes" (Translators for Peace 2003). Other practice-oriented networks, such as Translators without Borders, share a desire to provide free translations to humanitarian organizations and thus a belief that translators should volunteer their skills to non-profit organizations. Values may also include those of many professional networks, where members are linked by a shared commitment to ensuring, for instance, that they do not accept work they are unqualified to do (e.g. ATIO, ATA) or that all translations are revised before being submitted to the client (e.g. BQTA).

\subsubsection{Geographic location}

The fact that networks lack strictly defined boundaries (c.f. Gross Stein and Stren 2001: 5) means that some networks are more geographically dispersed than others. In some networks, actors may be located in the same country, city or institution, while in others, actors may be dispersed throughout many countries. Similarly, some networks are composed primarily of actors from a single institution or company (e.g. researchers in a translation department at a university), while others may include actors from various branches of an institution (e.g. a translation agency with multiple offices) or from many institutions, associations or companies. A network with a high concentration of members from a single institution or geographic location would be considered a mainly local network, while a network with members not concentrated in a single country would be considered international. Many networks do, of course, fall somewhere between these two poles.

Examples of networks in which most members are located mainly in the same geographic area include profession-oriented networks such as the Australian Institute of Interpreters and Translators, the LTAC or the Organización Mexicana de Traductores. In these three networks, almost all members reside within Australia, Canada and Mexico respectively. Highly local research-oriented networks include the Canadian Association for Translation Studies (CATS). Most online practice-oriented networks are international, but local practice-oriented networks also exist: a network of in-house translators at the same agency, company or department, for instance, would be a local practice-oriented network, just as researchers from the same academic institution would comprise a local research-oriented network. 
Examples of very international networks comprised of actors from multiple geographic locations are multinational translation agencies, which consist of translators from many countries, or online practice-oriented networks such as Aquarius. com, which has members in ten countries. A research-oriented network such as the European Society for Translation Studies (EST), though localized within a single continent, is international because it is composed of members from many European countries, as well as several from the United States and Canada and one from Taiwan.

Note that the term international has been chosen over global to refer to networks comprised of actors from multiple countries. This term was chosen because international networks may have a geographically diverse membership, but it would be virtually impossible for a single network to be comprised of actors from all parts of the world. Consider, for instance, a profession-oriented network like the ATA, where actors must be able to work in one of the language pairs that are a sub-focus of the network. In this case, language pairs must include English. Even a very international network such as ProZ cannot be considered "global" because for actors to interact, they must be able to at least understand the language(s) in which the resources for this network (e.g. website, forum(s), articles) are available. While some of the larger online practice-oriented networks have made many resources accessible in several languages, most of the networks have made their services available in only one or two. So, while users of the ProZ network are able to view the website in English, Spanish, Hungarian, Romanian, Brazilian Portuguese, German, Albanian, Latvian and Russian, and those at TranslatorsBase.com can choose from English, Portuguese, German, French, Dutch, Spanish, Italian and Polish, those at Language123 must browse in English or Spanish, and those at TranslatorsCafé only in English. ${ }^{6}$ Even sites that have been made available in multiple languages cannot target professionals working in every language pair. ${ }^{7}$ In addition, because many international networks rely on computer-mediated communication (a structural variable that will be discussed in section 1.3.5), members without access to a computer have limited or no access to the mailing lists, forums, job postings or website through which actors in the network usually interact.

\subsubsection{Membership requirements}

While some networks have virtually no restrictions on who can become a member, others have very strict criteria. Membership requirements greatly affect whether the network is comprised of only professionals (e.g. a translation firm), both professionals and non-professionals (e.g. ProZ, Japan Association of Translators), only translation companies (e.g. Belgian Quality Translation Association), only associations and institutions (e.g. International Federation of Translators), only individuals (e.g. ATIO), both translation agencies and individuals (e.g. TranslatorsCafé), etc. Membership requirements may also affect whether actors in a network reside or work in a single country, or whether they are dispersed throughout many regions. Compare for instance, the American Literary Translators Association and the Literary Translators' Association of Canada: while the ALTA, on its Membership Information page, "invites the active participation of all those interested in literary translation," the LTAC restricts full membership to Canadian citizens or permanent residents who have published a book-length literary translation (or equivalent). ${ }^{8}$ Other profession- 
oriented networks, including OTTIAQ, the ATA or the ISTC, also restrict full membership to individuals or companies considered "professional." Such members must usually meet certain qualifications, notably with respect to education and experience. In some cases, a test must be passed before members will be accorded the status of "professional" and full membership granted.

In networks with few membership requirements, the attributes of actors are often particularly diverse. Many online practice-oriented sites such as ProZ or TranslatorsCafé, for instance, are intended for language professionals and agencies, but any Internet user is able to create a profile and/or pay membership fees to belong to the network. For this reason, many of these networks are composed of actors with varying levels of knowledge, experience and education.

In networks where few or no restrictions are placed on membership, determining who is a member of the network is often difficult. In section 1.0, it was stressed that networks do not have defined boundaries. Nonetheless, in networks where few membership requirements exist, the exact number of members is often particularly difficult to determine. In many online translation networks, for instance, the number of registered members changes on a daily basis, which makes analyzing these networks especially complicated. Moreover, unregistered members are also able to interact with registered members by offering translation projects (business transactions), for instance, or regularly visiting the network website and reading forum postings (exchanges of non-material resources). Thus, official lists of members may not actually represent the number of actors in the network. In networks with more restrictive membership requirements, the boundaries of the network also expand and contract as members join and leave, but because fewer individuals, organizations or companies are eligible to join, the boundaries do not usually change as rapidly as they do in networks with fewer membership requirements.

\subsubsection{Computer mediation}

The extent to which members of a translation network rely on computer aids to interact affects the ties among members and the types of exchanges that will take place. Virtually all international networks must rely on some form of computer-mediated communication (CMC), but most local networks do so as well, though often to a lesser extent.

Computer-mediated communication refers to interactions that take place among actors using computers. Once limited to text-based communication (e.g. email or discussion forums), CMC now also includes auditory (e.g. Skype, Google Talk) and graphic (e.g. videoconferencing) communication (Herring 1996: 1-10). CMC can be very similar to in-person communication. Barnes (2001), for instance, asserts that correspondence occurring over the Internet is bidirectional, that individuals communicating over the Internet act as though they were communicating in-person, and that written language is shared online in much the same way as spoken language is shared in-person (2001: 10). Moreover, since oral communication can now occur online through services such as Skype or Google Talk, the ties among actors in a large, international network where interactions are primarily computer mediated may be very similar to those within a local network where actors interact almost entirely on a face-to-face basis. 
So, while the computer-mediation variable may not directly affect whether the ties among actors or subgroups of actors are primarily strong or weak, it does affect the types of interactions that will take place. In a network in which greater emphasis is placed on $\mathrm{CMC}$, interactions will occur primarily through email, instant messaging, forums or mailing lists, for instance, while in networks with less emphasis on $\mathrm{CMC}$, interactions will occur more often in-person.

Computer-mediated communication can also affect the attributes of actors in a network. Because CMC allows actors to live in different countries and still maintain ties, it facilitates diversity in networks. Some examples from networks where members interact almost entirely through CMC will help illustrate this point. The Globalization and Localization Association, a profession-oriented network, is composed of companies from 34 countries that range in size from 1-10 employees (130 members) to more than 500 (16 members). In the practice-oriented network Aquarius. com, most registered members reside in 10 European or North American countries, though another 10,000 registered members live in several other countries. Without computers to support interactions, such diversity would not be possible.

\subsubsection{Relations}

Relations between pairs of actors may vary within a single network: one actor may be linked with others in the same network in a variety of ways, while in other networks, actors may be connected by only one type of relation. For instance, while some members of a research-oriented network may be linked by the transfer of non-material resources, such as articles or conference announcements, others may be connected only by material exchanges in the form of translation services for payment.

\subsubsection{Governance}

Translation networks are governed in various ways. Some networks are best described as formal, the term Clark (1998) proposes to describe networks with a formal constitution and organization, a well-defined management structure and invited participation based on "criteria of merit or peer review" (1998: 1-2). ${ }^{9}$ Such networks resemble what Gross Stein and Stren describe as a “hub' with 'spokes” (2001: 12), in that the relationships of exchange linking actors in the network "radiate out from a core to the nodes, in a relatively centralized structure" (2001: 12). Examples of translation networks with a formal constitution and a core group of actors who form an executive council or board of directors include profession-oriented networks such as ATIO, the ATA and the South African Translators' Institute and researchoriented networks such as CATS, the EST and IATIS. Informal networks, by contrast, have no formal organization or governance. Clark states such networks can arise when two or more individuals come together "for conversation, for exchange of information, or [to] allow for discussion to create new knowledge" (1998: 9). He further argues that in many cases, informal networks begin and end within a short period of time because the purpose of the network has been met and the ties between the actors are no longer necessary (1998: 9). Informal networks correspond to Gross Stein and Stren's decentralized networks, where meetings usually take place on an ad hoc basis, members have considerable control over how funds are managed and reported, and no formal structure exists (2001: 12). Globally, any number of informal translation networks exist, given that any group of two or more translators 
exchanging (non-)material resources can be considered a network. Some examples of translation networks with a relatively informal structure can be found on Yahoo!, Google and msn Groups, where any Internet user can start a new group, actors are governed by very few rules, and few, if any, participation restrictions exist.

\section{Analyzing Translation Networks}

To illustrate how the framework described in section 1 could be applied, this paper will conclude with an analysis of a practice-oriented translation network: TranslatorsCafé, one of the largest translation networks encountered during the research for this paper. This network will be analyzed on the basis of two variables - relations and computer mediation - to determine how computer mediation affects ties among actors and to explore the effects of computer mediation and ties on new and experienced language professionals who exchange non-material resources.

Launched on August 1, 2002, TranslatorsCafé now has more than 50,000 registered members (http://www.TranslatorsCafé.com/cafe/Stats.asp). ${ }^{10}$ These membership figures change very rapidly, however. According to the TranslatorsCafé site administrator, the network saw an average of 54.8 new members register each day in the 30 days prior to February 10, 2007. Approximately 1000 members registered each month between January and October 2006. In addition to its being one of the largest translation networks, TranslatorsCafé was also chosen for study because interactions among actors in the network are primarily computer-mediated, so quantitative data on the relations between actors are more readily available than in networks where interactions are not primarily computer-mediated. The quantitative data from the TranslatorsCafé website and site administrator have been complemented by qualitative data obtained by surveying members of the network.

\subsection{Relations and computer-mediated communication in the TranslatorsCafé network}

As discussed in section 1.3.6, actors in the TranslatorsCafé network may be linked by two types of relations: exchanges of material resources (e.g. business transactions) and non-material transactions (e.g. discussions). This section focuses only on the latter type of relation and explores strong and weak ties among actors to determine whether strong-tie relationships can exist in a largely CMC-based network, whether weak ties can be useful to language professionals, and whether large CMC-driven networks offer language professionals advantages not found in networks where interactions are not usually computer-mediated.

Ties among actors will, of course, vary from one network to another and even between subgroups of actors within the same network. Weak and strong ties exist in both networks where interactions are almost entirely computer-mediated, as well as in networks where actors do not depend as heavily on computers to communicate or exchange services. Ties are weak when contact between actors is infrequent or absent, reciprocal services seldom take place and relationships are not emotionally close (Constant, Sproull and Kiesler 1997: 304), while stronger ties occur as the frequency of contact increases and services are exchanged over a longer period. 
The fact that interactions between actors in a network are almost entirely computer-mediated does not necessarily mean that ties among these actors will be weak. The notion that online ties can also be as strong as in-person ties is supported by Wellman and Guila (1999: 345), who stress that both online and offline relationships may share characteristics associated with strong ties: frequent, companionable contact, mutual support and long-term contact. Moreover, the Internet is often used to complement, rather than replace, offline relationships. Thus, in the TranslatorsCafé network, members are able to arrange small-group meetings (called come togethers) in cities around the world so that they can meet face-to-face with members they otherwise interact with only online.

A preliminary analysis of interactions among actors in the TranslatorsCafé network would suggest that ties are primarily weak, if only due to the fact that computer-mediated communication has helped the network become very large and composed of actors with diverse backgrounds. Obviously, in a network with more than 50,000 members, the ties between all members cannot possibly be strong: frequent contact with such a large number of people would be nearly impossible, even if everyone spoke a common language. And initial statistics on the number of members who visit the network's website seem to support the weak-ties hypothesis: according to statistics obtained from the site administrator, in the 30 days prior to February 16, 2007, for instance, only 11,555 members had logged on to the TranslatorsCafé website. Thus, fewer than a quarter of registered members visited the site during that period, which would seem to indicate that contact between most TranslatorsCafé members is infrequent at best. However, closer study of the relations will determine whether strong ties also exist within this network.

One way actors are linked is through discussion forums, where members share questions, answers and insight about issues such as CAT tools, freelancing, and terminology. Because participation statistics on these forums can be collected and analyzed, they present a more detailed picture of the strength of ties in the TranslatorsCafé network. According to site statistics obtained from the TranslatorsCafé administrator, only 3,728 of the 52,081 members registered by March 2007 (7 percent) had ever posted a message in the discussion forum since it was introduced in January 2003. These figures are similar to those of the terminology forum: as of February 2007, 2,305 users (just under 5 percent) had ever posted a question, answer or comment since the forum was introduced in April 2006. However, many more users had passively participated in the terminology forum by receiving notifications of new questions. The 2,305 users were part of 11,300 TranslatorsCafé members who had chosen to receive email notifications of new postings in the terminology forum. These statistics indicate that by March 2007, about a fifth of all registered members were actively or passively participating in exchanges of terminology questions and advice.

While the discussion forum figures initially seem to show that most users are not interacting via the forums and that ties among actors are generally weak, comparison between the number of messages posted in the discussion forum and the number of users posting messages shows that just over 3,700 members posted 109,429 messages. A query of the site administrator's database reveals that the top twenty posters have actually posted more than a thousand messages each, with the top user responsible for more than 15,000 messages. These statistics would suggest that while 
the discussion forum is not widely used, a small percentage of members frequently post messages to it.

To help determine why the members in this subgroup regularly interact via the discussion forum, a survey was conducted over a two-week period in March 2007. Individual messages were randomly sent to 111 TranslatorsCafé members who had posted multiple messages on the discussion forum, inviting them to respond to an online survey. A total of 31 members who had posted at least 10 messages responded to this invitation and completed the survey. While the number of responses may initially seem low, it is important to note two things. First, because the discussion forum has been operating since January 2003, not everyone who has posted multiple messages is still a member of the TranslatorsCafé network. Second, because the survey was in English, only members who had posted a message on the Englishlanguage discussion threads were contacted. Finally, the site administrator indicated that of the 3,728 members who have posted messages, only about sixty percent have posted multiple messages: 1,519 registered users (about 40 percent of all posters) have posted only a single message since joining the network. Of the remaining 2,209 members who have posted more than one message, only 495 have posted 10 or more messages. Because the primary intent of the survey was to determine why users posted multiple messages, only users responsible for 10 or more postings were contacted. Since 111 of the 495 users who met this criterion were contacted and 31 of them responded, the survey represents 6 percent of eligible users. Moreover, 19 of the 31 respondents had posted more than 100 messages, which is ample representation for the 90 TranslatorsCafé members who meet this criterion.

The survey was designed primarily to determine how long posters had been members of the TranslatorsCafé network, how often posters read and posted messages in the discussion and terminology forums, whether the top posters (more than 500 messages) had been members for longer than members who had posted fewer messages, what motivated posters, and whether these motivations varied according to the respondent's experience as a translator and the length of time he or she had been a member of the TranslatorsCafé network.

Of the 10 respondents who reported posting more than 500 messages, ${ }^{11}$ all had been members of the TranslatorsCafé network for two or more years and only one had fewer than five years' experience as a translator. Most ( 7 of the 10 respondents) had more than 10 years' experience translating and in the past 12 months, more than half ( 6 of 10 respondents) had read postings in the discussion forum an average of once per day. Almost invariably (9 of the 10 respondents), they posted messages in the discussion forum to share their experience, help others, and feel like part of a community. ${ }^{12}$ However, five respondents also posted because they wanted to increase their visibility in the network, suggesting that they see the discussion forum as not just a means of exchanging ideas, but also a way to make themselves known to other language professionals. One of the 10 respondents also saw the discussion forum as a way to "intellectually explore various issues," which suggests that he or she was particularly interested in exchanging ideas with other members, rather than making new contacts.

The motivations provided by the top posters were very similar to those offered by members who had posted 500 or fewer messages. Of these 20 respondents, 18 posted messages to share their experience, 17 wanted to help others, 10 added that 
they wanted to feel like part of a community, while 7 also wanted to increase their visibility in the network. One respondent also posted messages to discuss issues not related to translation.

Evidently, members who have posted 10 or more messages in the TranslatorsCafé discussion forum have done so for various reasons, rather than just one. Only 2 of the 31 respondents selected a single answer to this question ("to share experience"), indicating that most members are motivated by several factors. Since most of the 31 respondents posted messages to share their experience (27 respondents), help others (26 respondents) and/or feel like part of a community (20 respondents), the survey results indicate that many of the top posters are motivated by a desire to form stronger-tie relationships with other members. And reasons like "social" or "to discuss issues not related to translation," which were provided by two respondents, indicate that the discussion forum is also seen as a way to interact and remain in contact with colleagues virtually, similar to the way posters might have interacted in a translation office.

As Wasserman and Faust have established, when a subgroup of actors in a network has relatively frequent or direct ties, they form a cohesive subgroup (1994: 249). In the TranslatorsCafé network, one such subgroup would clearly be some or all of the 2,209 users who have posted multiple messages in the discussion forum. A larger subgroup of actors might be those who read these postings on a regular basis.

The following table compares the number of posts with the number of viewings of thirty recent threads in the TranslatorsCafé discussion forum. These statistics were compiled from the Recently Active Threads page on the TranslatorsCafé website on February 16, 2007. This page was chosen as an example because it represents a wide range of topics and is thus representative of the many types of discussions that take place among actors in the network. ${ }^{13}$

\begin{tabular}{|c|c|c|}
\hline Thread & Replies & Viewings \\
\hline \multicolumn{3}{|c|}{ Viewpoints, comments, advice } \\
\hline Thread 1 & 5 & 139 \\
\hline Thread 2 & 2 & 40 \\
\hline Thread 3 & 15 & 679 \\
\hline \multicolumn{3}{|c|}{ Announcements } \\
\hline Thread 1 & 282 & 27,905 \\
\hline Thread 2 & 5 & 364 \\
\hline \multicolumn{3}{|c|}{ Working as a freelancer } \\
\hline Thread 1 & 2 & 56 \\
\hline Thread 2 & 1 & 38 \\
\hline \multicolumn{3}{|c|}{ From language to literature } \\
\hline Thread 1 & 387 & 20,451 \\
\hline Thread 2 & 904 & 83.615 \\
\hline Thread 3 & 227 & 31,902 \\
\hline Thread 4 & 435 & 41,285 \\
\hline Thread 5 & 184 & 19,995 \\
\hline Thread 6 & 59 & 4131 \\
\hline Thread 7 & 6 & 109 \\
\hline
\end{tabular}




\begin{tabular}{|c|c|c|}
\hline \multicolumn{3}{|c|}{ All about garbage } \\
\hline Thread 1 & 23 & 524 \\
\hline Thread 2 & 1 & 51 \\
\hline \multicolumn{3}{|c|}{ Computer work and your health } \\
\hline Thread 1 & 81 & 9,987 \\
\hline \multicolumn{3}{|c|}{ Techniques } \\
\hline Thread 1 & 10 & 1,024 \\
\hline \multicolumn{3}{|c|}{ Jobs, outsourcers, payment } \\
\hline Thread 1 & 3 & 176 \\
\hline Thread 2 & 1 & 72 \\
\hline Thread 3 & 45 & 2,542 \\
\hline Thread 4 & 2 & 115 \\
\hline \multicolumn{3}{|l|}{ Subtitling } \\
\hline Thread 1 & 2 & 60 \\
\hline \multicolumn{3}{|c|}{ Machine translation } \\
\hline Thread 1 & 2 & 94 \\
\hline \multicolumn{3}{|c|}{ TCTerms features } \\
\hline Thread 1 & 16 & 450 \\
\hline Thread 2 & 4 & 93 \\
\hline \multicolumn{3}{|c|}{ Off-topic chit-chat } \\
\hline Thread 1 & 2 & 86 \\
\hline Thread 2 & 1 & 52 \\
\hline Thread 3 & 291 & 17,511 \\
\hline Thread 4 & 114 & 6,025 \\
\hline
\end{tabular}

While some topics are obviously more popular than others, all threads share a common trait: more viewings than replies. By comparing the replies and viewings columns, one can easily see that even if only a small subgroup of actors in the network is actively posting messages, a larger subgroup of actors - which likely includes the posters - is reading postings. In each of the thirty threads, the number of viewings greatly exceeds the number of postings, in many cases by a factor of 50 or 100 (e.g. Announcement thread 1 or Off-topic chit chat thread 3). The viewings statistics do include repeated views by the same person and requests from robots - such as a search engine spider - but the difference between the replies and views is still significant enough to conclude that more actors read forum postings than compose messages.

The results of the survey support this conclusion. Respondents were asked how often, in the past 12 months, they had read postings in the discussion forum (at least once per day, week, month, year, or not at all). They were also asked how often, in the past 12 months, they had posted a message in the forum. Of the 31 respondents, the vast majority read postings at least once per day (15 respondents) or week (13 respondents), but they posted messages less frequently. Only 5 respondents said they had posted a message at least once per day during the past 12 months, while another 9 said they did so at least once per week. Of the remaining 17 respondents, 10 had posted a message at least once per month in the past 12 months. Thus, even respondents who frequently posted messages read messages more often than they posted. The same tendency was found in the terminology forum (TCTerms): when respon- 
dents were asked how often, in the past 12 months, they had read messages posted in TCTerms, 9 reported reading postings at least once per day and 8 at least once per week. The remaining 14 respondents read postings once per month, year or not at all. And while the figures for active and passive participation in TCTerms are lower than those for the discussion forum, they follow the same pattern: 17 respondents had read postings on a daily or weekly basis, but only 7 had posted questions, comments or responses daily or weekly during the past 12 months. In fact, 8 of the respondents ( 25 percent) had not posted a question, response or comment to the terminology forum in the past 12 months, and their most common reasons for not doing so were that they were not interested in TCTerms (3 respondents), didn't have time to post in TCTerms (3 respondents), didn't think it was useful (2 respondents), ${ }^{14}$ or had had their questions answered through another translation network (2 respondents). ${ }^{15}$

The difference between participation rates in the discussion and terminology forums would seem to indicate that at least four subgroups are active in the TranslatorsCafé network: those who post and read messages in the discussion forum, those who post and read messages in TCTerms, and those who only read messages in one or both forums. As the survey results indicate, some overlap does exist between these subgroups, as many discussion forum posters had also posted questions, comments or responses in TCTerms, and many readers are also posters. The lower participation rate in the terminology forum by survey respondents can be explained by the fact that fewer TranslatorsCafé members in general have posted messages in TCTerms than in the discussion forum (5 percent vs. 7 percent), as well as by the fact that invitations to participate in the survey were sent only to TranslatorsCafé members who had posted in the discussion forum. Clearly, though, the primary goal was to determine why members participated in discussions and why the top posters had written so many messages, rather than why users participated in the terminology forum, so the members who were invited to participate needed to be active discussion forum posters. Thus, while the TranslatorsCafé network does seem to be primarily weak-tie given that so few users have ever actively posted terminology or discussion messages, stronger ties do exist among the subgroups of users who actively interact with others by posting and reading messages in the discussion and terminology forums. And other, larger subgroups passively interact by reading postings on a regular basis. Both active and passive participation in the forums can be beneficial to language professionals, as these forums help indicate which issues are important to members, what other language professionals expect of their peers, and what new developments - such as software releases, conferences, and publications - are occurring in the field.

In fact, these subgroups can, to various extents, be compared to what Wenger (1999) and Hoadley and Pea (2002) refer to as "communities of practice" (2002: 326). Wenger compares these communities to a node of strong ties, but with a focus on the practice that occurs in the process rather than on exchanges (Wenger 1999: 287). In a community of practice, the ties linking members are mutual engagement, joint enterprise and a shared repertoire: the members are all engaged in activities that define the community and are connected by the fact that they share a common practice (Wenger 1999: 73-79) - in this case translation or a related profession. As Wenger asserts, institutions do have some influence, but the way a practice is conducted is still determined by the community (1999: 80). This means that a community of 
language professionals like the discussion forum posters at TranslatorsCafé will largely influence what translation practices are considered "best" within the community. Thus, members of a community of practice will assess one another according to the "perceived appropriateness" of competence, commitment, activity, etc. (Hoadley and Pea 2002: 327). In future studies, the notion of perceived appropriateness and best practices could be further explored by analyzing the subjective comments made by forum posters. Such a study could help determine whether and how such "best practices" vary from one network to another, whether multiple communities exist within a single network, and how these communities affect the network's composition and structure.

So, while both strong and weak ties exist among members of TranslatorsCafé, ties among most actors seem to be weak given that only a small number of members actively and regularly write or read forum postings. Yet even weak-tie relationships can be beneficial to practising translators simply because a practice-oriented network like TranslatorsCafé is large and composed of actors with very diverse backgrounds: the network has hundreds or thousands of members in each of more than 49 language pairs, and anywhere from 300 to 5000 members in each of 21 African, Asian, European and North and South American countries. ${ }^{16}$ As Constant, Sproull and Kiesler conclude in their case study of weak ties in a technical network, diversity in a network increases the probability of obtaining a useful answer when experts are found in the various subgroups (Constant et al. 1997: 305; 318). However, they also note that numerous weak ties do not guarantee that an actor in a large network will receive more useful advice than he or she would have received through strong-tie relationships, since the experience and motivations of other actors in the weak-tie network will vary greatly. Consider, as an example, the results of the following searches conducted in the TranslatorsCafé database for English-to-Spanish translators. In February 2007, a total of 4,075 members were listed, but not all were native Spanish speakers: only 3,509 site members met this criterion. The number of years in which these members had been working as translators also varied widely, from less than one to more than twenty. So, an actor in the network may direct a question to members working in this language pair and reach a large number of other translators, but he or she will likely receive responses that range in usefulness. And although the probability that a translator will find an answer to an obscure question is also increased, since the question will reach a large number of people with very different experiences, not all of these users will answer the question: as of late February 2007, only 1,846 of the $51,102^{17}$ members registered at that time had ever answered a terminology question, for example. In a smaller network of strong-tie relationships, language professionals would not have access to the same range of experience, language pairs and fields of expertise, though the strong ties would mean that actors would be better able to judge the reliability of information received through the network and more likely to receive answers from a larger percentage of the network's members.

The TranslatorsCafé network, then, seems to offer advantages to new translators, who are able to determine, based on the comments and advice of members of the community of practice, the expectations that clients and other language professionals might have regarding their work, and how to resolve terminology, technology or other translation problems. Passive participation in the network's non-material 
exchanges provides newcomers with guidelines for future work, while active participation by posting in the forums allows new translators to actively seek responses to their questions. Experienced language professionals are able to exchange their questions and opinions with others and demonstrate their skills by providing terminology help or requesting assistance from others. For freelancers working from home, this network may be their only way to connect with other language professionals and keep abreast of new developments in the field. Moreover, because the terminology forums are rated by other members - questions can be given a numerical value based on their perceived difficulty and answers can be graded based on their perceived suitability - language professionals with highly rated questions and answers are constantly demonstrating their ability to translate well and submitting their translations for peer assessment, essentially making the TranslatorsCafé a venue for ongoing practice and skill development. And although actors can misrepresent themselves as experts relatively easily given the lack of membership requirements (other than Internet access and some ability to understand English), TranslatorsCafé does offer a number of advantages to members, including the ability to interact with language professionals of very diverse backgrounds who might otherwise have been inaccessible. Provided language professionals, students and those with an interest in the field take a critical approach to advice received through the network, it should prove a useful resource.

\section{Conclusions and possible future studies}

The large number of networks focusing on translation or a related profession demonstrates that formal and informal networks are playing an increasingly important role in the way the profession is practised. The fact that membership in many online networks is steadily increasing also indicates that both professionals and non-professionals are interested in interacting with colleagues, companies or more experienced professionals. Computer-mediated communication has allowed these networks to expand across borders, providing members with access to a wider range of colleagues than would have been available twenty or thirty years ago.

The framework outlined in this paper provides a basis for studying translation networks. It applies social network analysis to translation networks to study the ways in which language professionals interact. It can be used as a means of exploring how individuals, organizations and companies a) practise translation, b) produce and disseminate translation-related research, products or innovations, c) contribute to professionalism and d) determine how new language professionals will be trained. Future studies could include comparisons of translation networks on the basis of variables to determine, for instance, whether the stated values of a practice-oriented network are exemplified in the work produced by the actors, whether formal or informal governance of a research-oriented network results in wider dissemination of research, or whether strict membership requirements and formal governance in a profession-oriented network lead to better relations among actors than informal networks with few or no membership requirements. Translation networks could also be compared to networks in related fields to determine which variables researchoriented networks in history, sociology and translation studies, for instance, have in common and where they differ. Such studies would provide valuable insight into the 
effects networking has on the field and may even highlight ways in which researchoriented translation networks could more effectively disseminate, generate and promote knowledge.

\section{NOTES}

1. The author would like to thank Clara Foz (University of Ottawa) for her feedback on this paper. Portions of section 2 were previously presented at the Pathways to Translations Conference in Leiria, Portugal in November 2006 and questions from Mona Baker after the presentation were very helpful. The assistance of the TranslatorsCafé site administrator, Anatoly Zolotkov, was also invaluable, as he provided specific statistics about participation rates in the TranslatorsCafé discussion and terminology forums. Hi-Tronic provided hosting and php/MySQL coding for the survey described in section 2 .

2. Wasserman and Faust do describe other types of relations that may link actors in a network (e.g. kinship, evaluations such as friendship or respect, formal roles such as boss/employee or doctor/ patient, or even movement such as migration from one place to another) (c.f. Wasserman and Faust 1994: 37-38). However, these roles seem less suited to a network where actors are linked by a shared interest in translation. In the networks encountered during the research for this paper, actors were almost always linked by relationships based on exchanges of (non-)material resources.

3. This definition excludes networks of translators who are linked by a shared interest in non-translation issues, such as a network of translators linked by friendship or participation in social or sporting activities. While networks of translators, these are not translation networks.

4. For instance, does one consider only members of a professional order to be professionals or is a professional simply anyone who earns a living by practising translation (or a related profession)? Are unpaid volunteers professionals? Does one have to work full-time to be defined as a professional or is the mere act of exchanging language-related services for a fee enough?

5. The fact that the terms profession-oriented and practice-oriented have been used to refer to two types of networks does not mean that actors in practice-oriented networks are not professionals and do not adhere to some type of professional standards. Nor does it mean that actors in profession-oriented networks do not practise translation. The distinction rests on the fact that in some networks, actors are linked by a shared interest in promoting standards, establishing ways to recognize competence within the profession and enhancing the general public's perception of translation-related professions, while in other networks, actors place more emphasis on issues that arise during the translation process, such as resolving terminology problems, determining which agencies have poor payment practices and solving problems with CAT tools or specialized hardware.

6. However, the TranslatorsCafé Terms interface (http://www.TranslatorsCafé.com/tcterms/EN/ thDefault.aspx) has recently been translated into 13 languages and efforts are being made to translate the rest of the site as well.

7. Note, in these examples, that the sites have not been translated into languages officially spoken in Asia, even though there are more than 800 million native speakers of Mandarin Chinese compared to only 1.4 million native speakers of Latvian (see http://anthro.palomar.edu/language/language_ 1.htm and http://www.li.lv/en/?id=5). In fact, even GoTranslators, which is available in 30 languages, has been translated exclusively into languages officially spoken in Eastern and Western Europe (with the possible exceptions of Turkish and Russian).

8. The LTAC does, however, have two other membership categories with no voting rights: students, who must be enrolled in a translation or literature program, and associates, who need only be interested in literary translation.

9. While Clark uses this term to refer specifically to knowledge networks, it can apply to any of the network categories proposed in this paper.

10. While the membership figures of TranslatorsCafé and similar networks may initially seem quite high, they should probably be taken with a grain of salt. First, many members may have simply neglected to remove their profile after losing interest in the network or changing professions, while others may have created more than one profile. Second, since any Internet user with a valid email address is able to create a profile, the number of registered members does not necessarily equal the number of actual language professionals and agencies; some members may simply be interested in languages or translation, others may be students, while still others may have no connection to 
a translation-related profession at all. Finally, since most of these websites sell advertising space, site developers would be interested in ensuring the number of registered members remains high, as advertisers are more likely to invest their money in sites with higher traffic and more members.

11. Since only 39 TranslatorsCafé members had posted more than 500 messages in the discussion forum as of March 2007, these 10 respondents represent approximately one quarter of all users responsible for more than 500 posts.

12. When respondents were asked why they had posted messages in the TranslatorsCafé discussion forum, they were given a choice of five motivations (to share experience, to help others, to get help from others, to increase their visibility in the network, to feel like part of a community). They were also able to select "other" and elaborate in a text box, or indicate that they had not posted messages in the forum in the past 12 months. All respondents were able to select multiple motivations. These motivations were identical to those offered when respondents were asked about their motivations for posting questions, comments or responses in TCTerms.

13. Although these figures were collected in a single day, the ratios are similar to those of the most active threads on ProZ network, in samples taken on two other occasions.

14. One such respondent added that the terminology forum was for "wannabes rather than professionals."

15. Respondents could select more than one reason for not participating in the terminology forum, which explains why the figures do not add up to 8 .

16. Another 7,800 members live outside these countries.

17. This figure includes 3,895 job posters, agencies and agency representatives, as well as 47,207 linguists.

\section{REFERENCES}

BARnes, S. B. (2001): Online Connections: Internet Interpersonal Relationships, Cresskill, NJ, Hampton Press.

Clark, H. C. (1998): Formal Knowledge Networks: A Study of Canadian Experiences, Winnipeg, International Institute for Sustainable Development.

Constant, D., Sproull, L. and S. Kiesler (1997): “The Kindness of Strangers: On the Usefulness of Electronic Weak Ties for Technical Advice," in Kiesler, S. (ed.), Culture of the Internet, Mahwah, N.J., Lawrence Erlbaum Associates, pp. 303-322.

EUROPEAN SOCIETY FOR TRANSLATION STUDIEs (1992): EST Constitution, <http://www.esttranslationstudies.org/>.

Gross Stein, J. and R. Stren (2001): "Knowledge Networks in Global Society: Pathways to Development," in Gross Stein, J., Fitzgibbon, J. and M. Maclean (eds.), Networks of Knowledge: Collaborative Innovation in International Learning, Toronto, University of Toronto Press, pp. 3-28.

Hall, S. (1996): “The Question of Cultural Identity," in Hall, S., Held, D., Hubert, D. and K. Thompson (eds.), Modernity: An Introduction to Modern Societies, Cambridge, Blackwell Publishers, pp. 596-634.

Herring, S. C. (1996): “Introduction," in Herring, S. C. (ed.), Computer-Mediated Communication: Linguistic, Social and Cross-Cultural Perspectives, Amsterdam/ Philadelphia, John Benjamins Publishing Company, pp. 1-10.

Hoadly, C. and R. D. Pea (2002): "Finding the Ties that Bind: Tools in Support of a KnowledgeBuilding Community," in Renninger, K. A. and W. Shumar (eds.), Building Virtual Communities: Learning and Change in Cyberspace, Cambridge/New York, Cambridge University Press, pp. 321-354.

Jones, S. G (1997): “The Internet and its Social Landscape,” in Jones, S. G. (ed.), Virtual Culture: Identity and Communication in Cybersociety, London, Sage Publications, pp. 7-35.

KIDD, M. (2007, February 21): "Over 47,000 Language Professionals Joined ProZ.com in 2006," $<$ http://www.proz.com/employers/news?press_id=18>.

KILduff, M. and W. Tsai (2003): Social Networks and Organizations, London/Thousand Oaks, California/New Delhi, Sage Publications Ltd. 
LOCALIZATION WORLD NETWORK (n.d.): User guide, <https://216.18.156.115/localizationworld/ downloads/userGuide.pdf>.

Thompson, G. F. (2003): Between Hierarchies and Markets: The Logic and Limits of Network Forms of Organization, Oxford, Oxford University Press.

TranslatoRS FOR PEACE (2003): The Charter of Translators for Peace, <http://web.tiscali.it/ traduttoriperlapace/>.

Wasserman, S. and K. Faust (1994): Social Network Analysis: Methods and Applications, Cambridge, Cambridge University Press.

Wellman, B. and M. Gulia (1999): "Net Surfers Don't Ride Alone: Virtual Communities as Communities," in Wellman, B. (ed.), Networks in the Global Village: Life in Contemporary Communities, Boulder, Colorado, Westview Press, pp. 331-366.

Wellman, B. and S. D. Berkowitz (1988): "Introduction: Studying Social Structures," in Wellman, B. and S. D. Berkowitz (eds.), Social Structure: A Network Approach, Cambridge, Cambridge University Press, pp. 1-14.

Wenger, E. (1999): Communities of Practice: Learning, Meaning, and Identity, Cambridge, Cambridge University Press.

\section{APPENDIX}

\section{Translation networks}

Not exhaustive, this list provides examples of networks that fall into each of the four categories

\section{Profession-oriented:}

American Literary Translators Association (ALTA) www.literarytranslators.org/

American Translators Association (ATA) www.atanet.org

Asociación Argentina de Traductores e Intérpretes www.aati.org.ar

Association de l'industrie de la langue/Language Industry Association www.ailia.ca

Association of Translation Companies www.atc.org.uk/index.html

Association of Translators and Interpreters of Ontario (ATIO) www.atio.on.ca

Australian Institute of Interpreters and Translators (AUSIT) www.ausit.org

Avtranslators.org (network of audiovisual translators) www.avtranslators.org

Belgian Quality Translation Association (BQTA) www.bqta.be

Globalization and Localization Association (GALA) www.gala-global.org

Institute of Scientific and Technical Communicators www.istc.org.uk

International Federation of Translators www.fit-ift.org

Literary Translators' Association of Canada/Association des traducteurs et traductrices littéraires du Canada www.attlc-ltac.org/

Localization World Network www.localizationworld.com/network/index.php

Network of Translators in Education/Réseau des traducteurs et traductrices en éducation www.rte-nte.ca

Ordre des traducteurs, terminologues et interprètes agréés du Québec (OTTIAQ) www.ottiaq.org

Organización Mexicana de Traductores (OMT) www.omt.org.mx

Sección Autónoma de Traductores de Libros de la Asociación Colegial de Escritores de España (ACEtt) http://www.acett.org/

South Africa Translators' Institute www.translators.org.za

Union Nationale des Experts Traducteurs-Interprètes près les Cours d'Appel (UNETICA) www.unetica.fr 
Practice-oriented:

Aquarius www.aquarius.net

Arab Translators Network-Arab Professional Translators Society (ATN-APTS) www.arabtranslators.net/

Babelport.com www.babelport.com/

Foreignword http://foreignword.biz/ and www.foreignword.com

French_translation http://tech.groups.yahoo.com/group/French_translation/

GoTranslators www.gotranslators.com/

Language123: The Translation Marketplace language123.com

Manga_Translations http://groups.yahoo.com/group/Manga_Translations/

ProZ: The Translation Workplace www.proz.com

Russian Interpreters Network www.russianinterpreter.org

Russian Language Translators http://tech.groups.yahoo.com/group/ruslantra/

TRADUguidewww.traduguide.com

TranslatorPlanet www.translatorplanet.com

TranslatorsBase www.translatorsbase.com

TranslatorsCafé www.TranslatorsCafé.com

Translators without Borders www.translatorswithoutborders.org

Japan Association of Translators http://www.jat.org/about/about-e.html

Translators for Peace http://web.tiscali.it/traduttoriperlapace/

\section{Education-oriented:}

Association canadienne des écoles de traduction (ACET)/Canadian Association of Schools of Translation (CAST) http://www.uottawa.ca/associations/acet/

\section{Research-oriented:}

American Translation and Interpreting Studies Association (ATISA) http://appling.kent.edu/ATISA/ATISAHome.html

Asociación Ibérica de Estudios de Traducción e Interpretación (AIETI) www.aieti.net

Canadian Association for Translation Studies/Association canadienne de traductologie www.uottawa.ca/associations/act-cats/

Centre for Translation and Textual Studies (CTTS) www.ctts.dcu.ie/index.htm

European Society for Translation Studies (EST) www.est-translationstudies.org/

Hong Kong Translation Society http://hkts.org.hk/index.html

Intercultural Studies Group http://isg.urv.es/isg.htm

International Association for Translation and Intercultural Studies www.iatis.org 